\title{
An empirical study for ranking insurance firms using a hybrid of data envelopment analysis and neural network
}

\author{
Ahmad Makui and M. Emrani Noushabadi*
}

Department of Industrial Engineering, Iran University of Science \& Technology, Tehran, Iran

\begin{tabular}{|c|c|}
\hline$\overline{\text { ART I C LE I N F O }}$ & AB S T R A C T \\
\hline $\begin{array}{l}\text { Article history: } \\
\text { Received June 26, } 2012 \\
\text { Received in Revised form } \\
\text { August, } 12,2012 \\
\text { Accepted } 15 \text { September } 2012 \\
\text { Available online } \\
\text { September } 172012 \\
\text { Keywords: }\end{array}$ & $\begin{array}{l}\text { One of the primary concerns with data envelopment analysis arises when the number of inputs } \\
\text { and outputs increases. In such a case, required computations will become time consuming and } \\
\text { there is a concern on developing some hybrid methods to increase the capability of this method. } \\
\text { In this paper, a combination of data envelopment analysis and multi-layer neural network is } \\
\text { proposed, in a case study, for predicting the performance of Alborz insurance subsidiaries in } \\
\text { large cities in Automobile insurance firms. This research can be used in the future databases for } \\
\text { performance prediction. On the other side, these results can aid Alborz insurance in its future }\end{array}$ \\
\hline
\end{tabular}

Data envelopment analysis

Neural network

Insurance firms

\section{Introduction}

Data envelopment analysis (DEA) is a linear programming method used for calculating the relative efficiency of various decision-making units. During the past few decades, data envelopment analysis has been considered significantly as a technical method of efficiency measurement. This method is widely applied to calculate the efficiency of public and private organizations such as banks, airports, hospitals, universities, factories and insurance companies (Charnes et al., 1978).

Complicated calculations are imposed by data envelopment analysis method when there are data collections with different input/output variables as well as a great number of decision-making units. There are several alternative to handle such problems and one of them is to use neural network. Emrouznejad and Shale (2009), for instance, presented a combined neural network and DEA for measuring efficiency of large scale datasets. They explained that DEA for a large dataset with different inputs/outputs normally needs huge computer resources in terms of memory and CPU time

\footnotetext{
* Corresponding author. Tel: +989125464363

E-mail addresses: mostafa.emrani@yahoo.com (M. Emrani Noushabadi) 
and to handle this issue, they proposed a neural network back-propagation DEA to address this problem for the very large-scale datasets. According to Emrouznejad and Shale (2009), neural network needs relatively less computer memory and CPU time compared with conventional DEA methods. Wu (2009) used hybrid of DEA and neural network for measuring the performance of different suppliers. They implemented two models: Module 1 applied DEA and classifies suppliers into efficient and inefficient clusters depending on the resulting efficiency scores while the second model utilized firm performance-related data to train DT, NNs model and applied the trained decision tree model to new suppliers.

Tsai et al. (2009) built the consumer loan default forecasting model through performing an empirical analysis on the customers of unsecured consumer loan from a certain financial institution in Taiwan, and adopted the borrower's demographic variables and money attitude as the real-timeaneous discriminant data. They also constructed respectively through four predicting methods, such as DA, LR, NN and DEA-DA, to compare the suitability of their proposed models. They reported that DEADA and NN were possessed better predicting capability and they were the optimal predicting framework, which the study longing for. The study also showed that the default loan predicting model would be possessed higher level of predicting capability after added money attitude.

Samoilenko and Osei-Bryson (2010) proposed a five-step model to determine whether the difference in the scores of scale heterogeneous DMUs is due to the heterogeneity of the levels of inputs and outputs, or whether their efficiency of conversion of inputs into outputs is the major reason. The method is another application of DEA and neural network. Mostafa (2009) studied the efficiency of top Arab banks based on DEA and neural networks. The study implemented a probabilistic neural network (PNN) and a traditional statistical classification technique to model and to classify the relative efficiency of top Arab banks. Accuracy indices were implemented to assess the classification accuracy of the models. Results indicate that the predictive accuracy of NN models is quite similar to that of traditional statistical methods. They also reported that the NN models had a great potential for the classification of banks' relative efficiency due to their robustness and flexibility of modeling algorithms. Azadeh et al. (2011) evaluated the effect of personnel efficiency attributes on total efficiency through DEA and Artificial Neural Network (ANN) and Rough Set Theory (RST). Wang et al. (2009) proposed a fuzzy DEA neural network technique to measure the relative efficiency of professional construction management.

This study presents an alternative method in which neural network and data envelopment analysis are employed to analyze Alborz insurance company data. Discovering a network for forecasting the unit efficiency is the goal of mentioned method. This method significantly decreases the number of calculations. Finally, to investigate the efficiency of Alborz insurance company agents in different cities, its data are considered. This investigation results will aid Alborz insurance in its future investments based on its agent's grade in different cities.

In this article, data envelopment analysis technique and efficiency calculation method is described in section 2. In section 3, multi-layer neural network is presented and the efficiency prediction algorithm which is a combination of data envelopment analysis method and multi-layer neural network is described. Analyzing of the Alborz insurance subsidiaries efficiency in different cities has been mentioned in section 5 and finally, in section 6, the conclusion has been presented.

\section{Data envelopment Analysis}

Data envelopment analysis is a calculation method of the decision-making units' performance in which linear programming techniques are used to analyze the input/output vectors. The existence of several outputs for several inputs in one issue simultaneously is one of the benefits of data envelopment analysis. In this method, performance is calculated based on inputs and outputs. Consider a decision-making set $\left\{D M U_{j} \mid j=1, \ldots, n\right\}$, to calculate the performance, $m$ input variables 
$\left\{x_{i j} \mid i=1, \ldots, m\right\}$ as well as $s$ output variables $\left\{y_{r j} \mid r=1, \ldots, s\right\}$. In the general data envelopment method suggested by Charnes et al. (1978), (DEA, CCR), the performance of decision-making unit $j_{0}\left(D M U_{j_{0}}\right)$ is defined in model 1 as follows.

Model 1: output oriented model (CCR):

$$
\begin{array}{ll}
\max \quad \phi & \\
\text { subject to } & \\
\sum_{i=1}^{m} \lambda_{i} x_{i j}+S^{+}=x_{i j_{0}} & \forall i \\
\sum_{r=1}^{s} \lambda_{i} y_{r j}-S^{-}=\phi \cdot y_{r j_{0}} & \forall r \\
S^{+}, S^{-} \geq 0 & \forall i, r \\
\lambda_{j} \geq 0 & \forall j
\end{array}
$$

where $x_{i j}$ is the value of $i^{\text {th }}$ input in the $j^{\text {th }}$ decision-making unit, $y_{r j}$ is the value of $r^{\text {th }}$ input in the $j^{\text {th }}$ decision-making unit and $j_{0}$ is the decision-making unit which its performance is calculated. By assuming that $\phi^{*}$ is the optimum value of $\phi$, the decision-making unit $j_{0}$ will become efficient, if $\phi^{*}=1$ and optimum value of $S^{+}, S^{-}$be equal to zero $(\forall i, r) \cdot S^{+}$and $S^{-}$are auxiliary variables. The presence of positive auxiliary variables in the $i^{\text {th }}$ input $\left(S_{i}^{*}>0\right)$ and $r^{\text {th }}$ output $\left(S_{r}^{*}>0\right)$ is indicative of the inefficiency of $i^{\text {th }}$ input as well as $r^{\text {th }}$ output. Owing to the fact that model 1 expands the outputs of decision-making units in the production space about fixed inputs, this model is an output oriented model. To derive $n$ optimum value of $\left(h^{*}, \lambda^{*}\right)$, this model should be solved $n$ times and should be evaluated one time for each decision-making unit. There are complete examples of data envelopment analysis method applications in (Cooper et al., 2004; Sadjadi et al., 2011; Ghasemi Mobtaker et al., 2012; Sadjadi et al., 2011). There are several special software packages developed because of the complicated calculations of data envelopment analysis.

In this article, to derive the predictive network of Alborz insurance branches performance in some main cities, the linear programming DEA model is implemented for calculating the performance of each unit. The results of the implementation of DEA model has yielded efficient units for some branches. Next, we introduce neural network for possibly improving efficiency of DEA implementation.

\section{Neural network}

Fig. 1 shows a feed forward multi-layer architecture, which is the same as this article schemes. The first application of neural networks was proposed in the $50^{\text {th }}$ decade of $20^{\text {th }}$ century, when Frank Rosenblatt introduced the perceptron network in 1958. At the same time, Bernard Widerow (Rosenblatt, 1958) introduced the linear adaptive neural network, Adeline, with new training rule which its structure was similar to perceptron network.

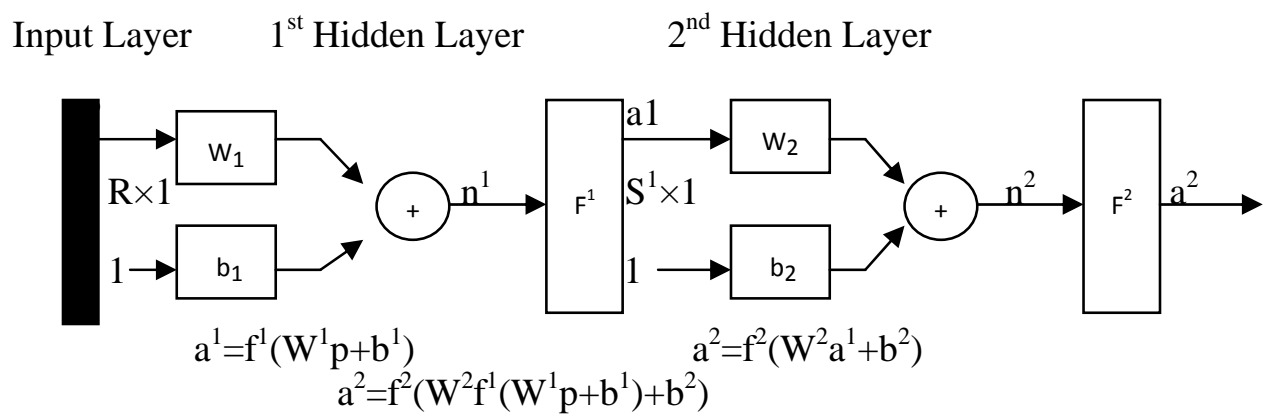

Fig. 1. Multi-layer neural network (Hagan et al., 2002) 
The progress of neural networks continued until $70^{\text {th }}$ decade of $20^{\text {th }}$ century. In 1972 , Teo kohonen and James Anderson independently introduced new neural networks, which had the capability of usage as a storage element. Stefan Grossberg was studying on self-organizing networks in this decade. Doing research on neural networks in $60^{\text {th }}$ decade of $20^{\text {th }}$ century was less than researches in $80^{\text {th }}$ decade of last century because of the shortage of high-speed computers. In $80^{\text {th }}$ decade, the advancement of microprocessors technology resulted in introducing novel ideas in neural networks. Novel ideas and high technologies were two good factors for creating a renascence in the neural networks. There are two attitudes in this renascence of neural networks. The first one is the usage of a random mechanism for operation description of a wide range of recurrent networks, which can be used for data storage. This idea was proposed by John Hopfield, the American physician, in 1982. The second important idea, which was the improvement key of neural networks in $80^{\text {th }}$ decade, was the error back propagation algorithm introduced by Rumelhart et al. (1986). Neural networks were evolved by these two ideas. In recent decades, a lot of articles have been written and neural networks have been applied in different fields. Neural networks are developing theoretically and practically. The most improvements in the neural networks are associated with new structures and novel training methods. In this article, multi-layer perceptron networks in which the prediction is optimized by varying the hidden layers as well as the number of Neurons of these layers have been used.

\section{Multi-layer neural networks- data envelopment analysis}

Neural network inputs are the characteristics used for calculating the performance of DEA model and its outputs are the values, which should be predicted. Input layer is formed by neural network inputs and model output, the performance, forms the single neuron output layer of the prediction network. In this article, the number of hidden middle-layer is equal to one and the number of Neurons of this layer, which has a direct impact on the prediction accuracy is variable. To select the best network, 10 different networks are tested. Back propagation algorithm (Rumelhart et al., 1986) has been used for neural network weights training and Sigmoid activation function has been applied.

$$
\operatorname{Sigmoid}(x)=\frac{1}{1+e^{-x}}
$$

\section{Proposed model for predicting the performance of Alborz insurance subsidiaries}

In this section, we present the implementation of the proposed model of this paper for an insurance firm in Iran called Alborz. The insurance firm consists of different branches in various cities of the country. The proposed hybrid model determines the cities, which are efficient and create a model for predicting future data. Predictive network can be used in the future data of insurance and therefore, the solving of linear programming model in the data envelopment analysis is not essential. First, the input and output variables are introduced (Table1) and the training set of insurance database (includes 34 cities) are selected, randomly. This set includes 19 cities. Validation (9 members) and testing (6 members) sets are also selected, randomly. After set selection, the training of networks is prepared and its results are completely mentioned in Table 2. It's worth noting that to prevent over fitting, validation set has been used and the training will stop, if the accuracy in the training and validation set increases.

\section{Table 1}

Inputs and outputs of the proposed case study

\begin{tabular}{ll}
\hline Input & Output \\
\hline Number of branches in city & Number of financial damages in last year \\
Number of branches staff & The amount of financial damages in last year \\
Number of agents & The amount of received insurance premiums \\
\hline
\end{tabular}

The trained networks have been ordered in accordance with mean square error in training set. Owing to the fact that the data of test set are not used in the model in any stages of training, the obtained 
mean square error is representative of model network predictive power. Network-4 which has 4 Neurons in the hidden layer is selected as the best performance estimator because it has the least mean square errors in the test set. To investigate the accuracy of this network, the linear correlation between predicted values of this network and real values of performance which have been derived by data envelopment analysis model, have been compared.

\section{Table 2}

Selected networks training, validation and testing results for performance prediction of Alborz insurance subsidiaries

\begin{tabular}{|c|c|c|c|c|c|c|c|c|c|c|}
\hline \multirow{2}{*}{\multicolumn{2}{|c|}{ Title }} & \multicolumn{9}{|c|}{ Network } \\
\hline & & 4 & 8 & 9 & 2 & 6 & 5 & 3 & 7 & 10 \\
\hline \multicolumn{2}{|c|}{$\begin{array}{l}\text { The number of input layer } \\
\text { Neurons }\end{array}$} & 6 & 6 & 6 & 6 & 6 & 6 & 6 & 6 & 6 \\
\hline \multicolumn{2}{|c|}{$\begin{array}{l}\text { The number of hidden layer } \\
\text { Neurons }\end{array}$} & 4 & 8 & 9 & 2 & 6 & 5 & 3 & 7 & 10 \\
\hline \multicolumn{2}{|c|}{$\begin{array}{l}\text { The number of output layer } \\
\text { Neurons }\end{array}$} & 1 & 1 & 1 & 1 & 1 & 1 & 1 & 1 & 1 \\
\hline \multirow{3}{*}{$\begin{array}{l}\text { Mean } \\
\text { absolute } \\
\text { error }\end{array}$} & Training & 0.0521 & 0.0492 & 0.0494 & 0.0521 & 0.0511 & 0.0514 & 0.0531 & 0.0513 & 0.0515 \\
\hline & Validation & 0.1174 & 0.1074 & 0.1079 & 0.1168 & 0.1111 & 0.1105 & 0.1162 & 0.1105 & 0.1102 \\
\hline & Test & 0.113 & 0.119 & 0.1227 & 0.1187 & 0.1218 & 0.1226 & 0.1207 & 0.1227 & 0.1228 \\
\hline \multirow{3}{*}{$\begin{array}{l}\text { Mean } \\
\text { square } \\
\text { error }\end{array}$} & Training & 0.0047 & 0.0044 & 0.0043 & 0.0049 & 0.0046 & 0.0047 & 0.0051 & 0.0048 & 0.0048 \\
\hline & Validation & 0.0234 & 0.0208 & 0.0207 & 0.0241 & 0.0222 & 0.0221 & 0.0245 & 0.0222 & 0.0222 \\
\hline & Test & 0.0256 & 0.0281 & 0.0294 & 0.0299 & 0.0304 & 0.0311 & 0.0312 & 0.0314 & 0.0318 \\
\hline
\end{tabular}

Table 3 summarizes the results of linear correlation of the network number 4 by considering real values.

\section{Table 3}

The linear correlation of network No.4 with real values

\begin{tabular}{lll}
\hline Title & & Network No.8 \\
\hline \multirow{3}{*}{ Mean square error } & Training & 0.0047 \\
& Validation & 0.0234 \\
& Testing & 0.0256 \\
\hline Linear correlation(Testing Set) & & 0.8019 \\
\hline
\end{tabular}

This value is equal to 0.8019, which represents high predictive power of this network in this issue. At the end, the predicted and real values of three sets are demonstrated in Fig. 2, Fig. 3 and Fig. 4.

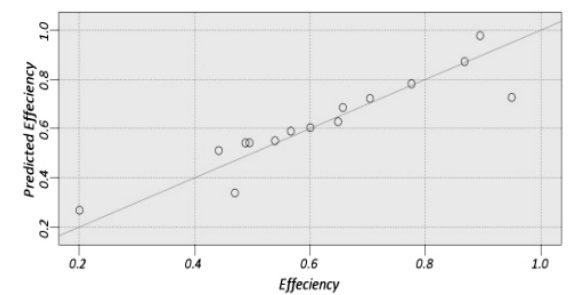

Fig. 2. predicted and real values diagram (training set)

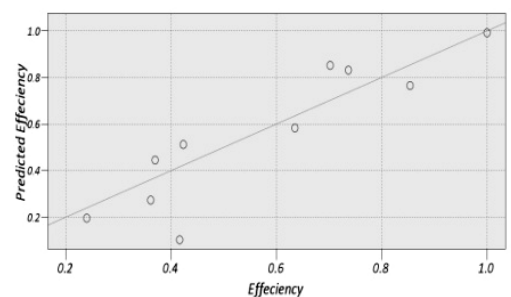

Fig. 3. Predicted and real values diagram (validation set)

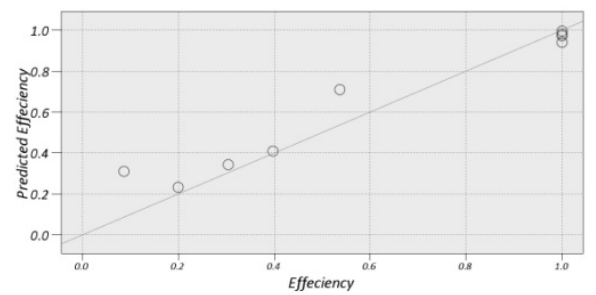

Fig. 4. Predicted and real values diagram (test set)

\section{Conclusion}

In this paper, we have presented a hybrid method based on data envelopment analysis and neural network to measure the relative efficiency of various similar units. The proposed model of this paper has been applied for a real-world case study of insurance company in Iran. The results show that the 
suggested network has the capability of performance prediction with high accuracy. The most important conclusion of this article is the usage of neural network and its application in the simplifying of performance prediction. This characteristic is very useful in databases with many records as well as various inputs and outputs.

\section{Acknowledgement}

The authors would like to thank the anonymous referees for constructive comments on earlier version of this paper.

\section{References}

Azadeh, A., Saberi, M., Tavakkoli Moghaddam, R., \& Javanmardi, L. (2011). An integrated Data Envelopment Analysis-Artificial Neural Network-Rough Set Algorithm for assessment of personnel efficiency. Expert Systems with Applications, 38(3), 1364-1373

Charnes, A., Cooper, W. W., \& Rhodes, E. (1978). Measuring the efficiency of decision making units. European Journal of Operational Research, 2, 429-444.

Cooper, W. W., Seiford, L. M., \& Zhu, J. (2004). Handbook on data envelopment analysis. Kluwer Academic, 2004.

Emrouznejad, A., \& Shale, E. (2009). A combined neural network and DEA for measuring efficiency of large scale datasets. Computers \& Industrial Engineering, 56(1), 249-254.

Ghasemi Mobtaker, H., Akram, A., Keyhani, A., \& Mohammadi, A. (2012). Optimization of energy required for alfalfa production using data envelopment analysis approach. Energy for Sustainable Development, 16(1), 81-89.

Hagan, M.T., Demuth, H.B., \& Beale, M.H. (2002). Neural Network Design. University of. Colorado Bookstore, Boulder, CO.

Mostafa, M.M. (2009). Modeling the efficiency of top Arab banks: A DEA-neural network approach. Expert Systems with Applications, 36(1), 309-320.

Rosenblatt, F. (1958). A probabilistic model for information storage and organization in the brain. Psychological Review, 65(6), 386-408.

Rumelhart, D.E., Hinton, G.E., Williams, R.J. (1986). Learning representations by back-propagating errors. Nature, 323, 533-536.

Sadjadi, S. J., Omrani, H., Makui, A., \& Shahanaghi, K. (2011). An interactive robust dataenvelopmentanalysis model for determining alternative targets in Iranian electricity distribution companies. Expert Systems with Applications, 38(8), 9830-9839.

Sadjadi, S.J., Omrani, H., Abdollahzadeh, S., Alinaghian, M., \& Mohammadi, H. (2011). A robust super-efficiency dataenvelopmentanalysis model for ranking of provincial gas companies in Iran. Expert Systems with Applications, 38(9), 10875-10881.

Samoilenko, S., \& Osei-Bryson, K.M. (2010). Determining sources of relative inefficiency in heterogeneous samples: Methodology using Cluster Analysis, DEA and Neural Networks. European Journal of Operational Research, 206(2), 479-487.

Tsai, M.C., Lin, S.P., Cheng, C.C., \& Lin, Y.P. (2009). The consumer loan default predicting model An application of DEA-DA and neural network. Expert Systems with Applications, 36(9), 1168211690.

Wang, C.H., Chuang, C.C., \& Tsai, C.C. (2009). A fuzzy DEA-Neural approach to measuring design service performance in PCM projects. Automation in Construction, 18(5), 702-713.

Wu, D. (2009). Supplier selection: A hybrid model using DEA, decision tree and neural network. Expert Systems with Applications, 36(5), 9105-9112. 